\title{
Can a multi-model approach improve hydrological ensemble forecasting? A study on 29 French catchments using 16 hydrological model structures
}

\author{
J. A. Velázquez ${ }^{1}$, F. Anctil ${ }^{1}$, M. H. Ramos ${ }^{2}$, and C. Perrin ${ }^{2}$ \\ ${ }^{1}$ Chaire de recherche EDS en prévisions et actions hydrologiques, Génie civil et génie des eaux, Université Laval, \\ Québec, Canada \\ ${ }^{2}$ Cemagref, Hydrosystems and Bioprocesses Research Unit, Parc de Tourvoie, BP 44, 92163 Antony Cedex, France
}

Received: 9 July 2010 - Revised: 19 November 2010 - Accepted: 19 November 2010 - Published: 28 February 2011

\begin{abstract}
An operational hydrological ensemble forecasting system based on a meteorological ensemble prediction system (M-EPS) coupled with a hydrological model searches to capture the uncertainties associated with the meteorological prediction to better predict river flows. However, the structure of the hydrological model is also an important source of uncertainty that has to be taken into account. This study aims at evaluating and comparing the performance and the reliability of different types of hydrological ensemble prediction systems (H-EPS), when ensemble weather forecasts are combined with a multi-model approach. The study is based on 29 catchments in France and 16 lumped hydrological model structures, driven by the weather forecasts from the European centre for medium-range weather forecasts (ECMWF). Results show that the ensemble predictions produced by a combination of several hydrological model structures and meteorological ensembles have higher skill and reliability than ensemble predictions given either by one single hydrological model fed by weather ensemble predictions or by several hydrological models and a deterministic meteorological forecast.
\end{abstract}

\section{Introduction}

In general, an ensemble forecasting system seeks to assess and to provide useful information on the uncertainty of hydrological predictions by proposing, at each time step, an ensemble of forecasts from which one can estimate the probability distribution of the predictant (the probabilistic forecast), in contrast with a single estimate of the flow for which no distribution is obtainable (the deterministic forecast). Ef-

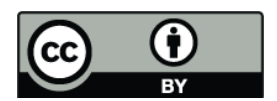

Correspondence to: J. A. Velázquez (juan-alberto.velazquez.1@ulaval.ca) forts towards the development of probabilistic hydrological prediction systems have been made with the adoption of ensembles of numerical weather predictions (NWPs). Several scientific programs thus address the issue of ensemble predictions in hydrometeorological forecasting chains: see for instance, the COST 731 action (Zappa et al., 2010), the MAP D-PHASE initiative (Zappa et al., 2008) and the Hydrological ensemble prediction experiment HEPEX (Schaake et al., 2007; Thielen et al., 2008). Several case studies have intended to evaluate the additional information provided by different available Meteorological Ensemble Prediction Systems (M-EPS) in a hydrological context (see the review by Cloke and Pappenberger, 2009). Most of these studies have investigated ensemble flow predictions from a single hydrological model set-up, over one catchment or a limited number of them. In these cases, only the uncertainty originating from weather predictions is assessed, through the use of meteorological ensembles. For example, the M-EPS of the European Centre for Medium-Range Weather Forecasts (ECMWF) was evaluated in the case studies reported by:

- Roulin and Vannitsem (2005) for two catchments in Belgium and a water-balance-based model;

- Bartholmes and Todini (2005) for the Po river basin and the TOPKAPI distributed hydrological model;

- Olsson and Lindström (2008) for 45 catchments in Sweden and the HBV model;

- Younis et al. (2008) for the Elbe river basin and the LISFLOOD distributed model;

- Jaun et al. (2008) and Jaun and Ahrens (2009) for the upper Rhine basin and the semi-distributed hydrological model PREVAH;

- Renner et al. (2009) for 134 sub-catchments of the Rhine river basin and the HBV model.

Published by Copernicus Publications on behalf of the European Geosciences Union. 
- Kalas et al. (2008) for the Morava catchment in the Danube River basin, and the European Flood Alert System (EFAS) based on the LISFLOOD model.

Some case studies use quantitative weather predictions coming from two or more sets of M-EPS, each coming from different meteorological centers (e.g., Thirel et al., 2008), and/or evaluate outputs from more than one hydrological model (e.g., Ranzi et al., 2009; Randrianasolo et al., 2010). However, ensemble flow prediction sets are usually investigated separately.

To provide ensemble predictions for hydrological applications, an ensemble of meteorological forecasts can also be constructed by combining deterministic forecasts from different weather agencies. For example, a case study is presented by Davolio et al. (2008) based on deterministic forecasts from six high-resolution limited-area models coupled with a distributed hydrological model for some events in the Reno catchment in Italy. Results showed that the tested system is promising for the prediction of peak discharges for warning purposes. The M-EPS for a single center only accounts for part of the uncertainties originating from initial conditions and model parameterization. The TIGGE network (THORPEX Interactive Grand Global Ensemble, Park et al., 2007) is a World Meteorological Organization project that searches to capture other sources of uncertainties associated with the meteorological model structure and the ensemble size, through the set up of a grand-ensemble database, which comprises M-EPS from different meteorological centers around the world. The TIGGE archive has been tested in hydrology in a combined multi M-EPS framework. Pappenberger et al. (2008) used data from seven M-EPS (216 members) as meteorological input to the European Flood Alert System (Thielen et al., 2009), based on the LISFLOOD distributed hydrological model, for the simulation of the October 2007 flood event in Romania. The results showed that the grand-ensemble provides more reliable predictions of flood events. He et al. (2010) used predictions from six meteorological agencies to drive a hydrological forecasting model during the July-September 2008 flood event in the Huai River basin in China. Their results indicated that the multi-model TIGGE archive is a promising tool for 10-dayahead discharge forecasting.

Although considered as an important contribution to the total uncertainty of flow predictions, uncertainties arising from the hydrological modeling are not often assessed. Recently, Dietrich et al. (2009) proposed to account for the uncertainty coming from weather ensemble predictions and the hydrological model. This was based on a multimodel superensemble of M-EPS forecasts, while the uncertainty of the hydrological model is represented by a parameter ensemble from the conceptual rainfall-runoff model ArcEGMO. Uncertainties from the structure of the hydrological model, i.e., in the mathematical representation of the hydrological processes involved in the rainfall-runoff transformation, were however not considered. An operational forecasting system that takes into account model uncertainty is presented by Hopson and Webster (2010) for the Brahmaputra and Ganges Rivers. It is based on the ECMWF 51-member ensemble prediction system and two hydrological models (semi distributed and lumped). In this system, multimodel discharge forecasts are generated for each ensemble member, by individually combining hydrological model outputs for the same ensemble member, according to the philosophy of multimodel regression weighting coefficients of Krishnamurti et al. (1999) and Georgakakos et al. (2004).

The aim of the present study is to evaluate and compare the performance and the reliability of different types of hydrological ensemble prediction systems (H-EPS), by taking into account uncertainties from the meteorological input and the hydrological model structure, as well as by exploiting all the outputs generated, instead of only retaining the single (combined) ensemble prediction. The scenarios are built on the basis of 16 different lumped rainfall-runoff model structures and 9-day ECMWF ensemble and deterministic forecasts. The systems were implemented over 29 French catchments, representing a large range of hydro-climatic conditions, and evaluated over a period of 17 months. Three types of ensembles were constructed:

1. 16-member ensemble (all 16 models are driven by the deterministic forecast),

2. 50-member ensemble (each individual model is driven by the 50-member M-EPS forecast),

3. 800-member ensemble (all 16 models are driven by the 50-member M-EPS forecast).

The performance of the forecasting ensembles is first compared with their deterministic counterpart. Then, the reliability of each H-EPS is assessed through reliability diagrams. The operational value of the H-EPS systems is tested through their ability to detect strong events, by evaluating hit rates, false alarm rates and the Relative Operating Characteristic for discharges exceeding the $90 \%$ quantile. Results are discussed in an operational perspective.

\section{Methodology}

Catchments and models are presented in this section, as well as the scores and tools used to evaluate the performance and reliability of the ensemble predictions.

\subsection{Catchments and hydro-meteorological data}

The study is conducted over 29 French catchments with areas ranging from $1470 \mathrm{~km}^{2}$ to $9390 \mathrm{~km}^{2}$. Catchments are spread all over France and represent a large variety of physical conditions in terms of size, topography, geology, soil, land use, and climate (Fig. 1). The mean annual rainfall ranges from 
Table 1. Main characteristics of the studied catchments.

\begin{tabular}{lcccc}
\hline & $\begin{array}{c}\text { Catchment } \\
\text { area }\end{array}$ & $\begin{array}{c}\text { Mean annual } \\
\text { rainfall }\end{array}$ & $\begin{array}{c}\text { Mean annual } \\
\text { potential } \\
\left(\mathrm{km}^{2}\right)\end{array}$ & $\begin{array}{c}\text { Mean annual } \\
\text { discharge }\end{array}$ \\
\hline Minimum & 1470 & 667 & 619 & $(\mathrm{~mm})$ \\
Median & 2990 & 948 & 684 & 130 \\
Maximum & 9390 & 1394 & 820 & 343 \\
\hline
\end{tabular}

$667 \mathrm{~mm}$ to $1394 \mathrm{~mm}$, while mean annual discharges vary between $130 \mathrm{~mm}$ and $789 \mathrm{~mm}$ (Table 1). A characteristic time scale for the hydrological response was evaluated for each catchment. In this study, this response time scale was evaluated through the shape analysis of observed flood hydrographs, as proposed by Sauquet et al. (2008). Dimensionless hydrographs were computed, while the response time is defined as one third of the median duration for which discharges are greater than half of the peak flow. For the studied catchments, the average response time corresponds to 3.2 days.

Temperature, rainfall and flow data are available at a daily time step over the period extending from 1970 to 2005, and were used for the calibration and validation of the hydrological models in each catchment. Observed data for the period 11 March 2005 to 31 July 2006 was used only for the evaluation of the forecasts. The forecast verification period is thus independent from the calibration/validation period. Rainfall data come from the meteorological analysis system SAFRAN of Météo-France (see Quintana-Seguí et al., 2008 for details). They consist of rainfall accumulated at a daily time step and available over France at an $8 \times 8-\mathrm{km}$ grid resolution. Temperature data were used to compute potential evapotranspiration using the formulation proposed by Oudin et al. (2005). Daily streamflow data come from the French database Banque Hydro that archives river water levels and flows for more than 3000 gauging stations in France (http://www.hydro.eaufrance.fr/). The length of available observed streamflow time series varies according to the catchment, with, on average, 29 years of available daily data for the catchment dataset used here.

\subsection{Rainfall forecasts from ECMWF}

ECMWF rainfall forecasts were available for the verification period of 17 months (11 March 2005 to 31 July 2006) and were provided at a $0.5^{\circ} \times 0.5^{\circ}$ lat/lon grid resolution over France. They consist of the ECMWF deterministic forecasts (M-DPS), based on the best estimate analysis, and the 50 perturbed forecasts of the M-EPS (see Buizza et al., 1999). Forecasts are issued at 12:00 UTC and extend over 240 h. Rainfall amounts were accumulated at 24-h time steps, starting at $0 \mathrm{~h}$ to match with observed daily data, which resulted in

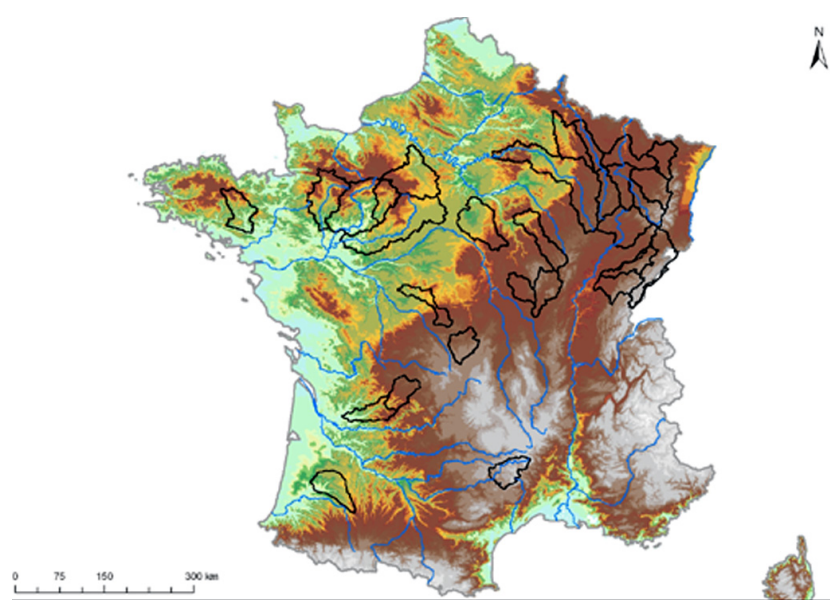

Fig. 1. Location of the 29 studied catchments in France.

nine daily lead times (hereafter, D1 to D9). No bias removal or disaggregation was performed. For each catchment, areal mean rainfall forecasts were computed by averaging the rainfall amounts of each grid above the catchment, weighted by the percentage of the catchment area inside the grid.

\subsection{Hydrological models}

The sixteen hydrological models applied in this study are lumped reservoir-type models and correspond to various conceptualizations of the rainfall-runoff transformation at the catchment scale. They are of low to moderate complexity: the number of parameters to calibrate against observed data ranges from 3 to 13. Table 2 lists the tested models, along with their number of optimized parameters. All the models include a soil moisture accounting procedure in their representation of the hydrological production function, but with various formulations (linear or non linear, possibly with several soil layers, etc.). The routing module includes from 1 to 5 linear or non linear stores, as well as unit hydrographs or pure time delays. Some of the models include a nonconservative function to adjust the water balance (correction factors of inputs or groundwater exchange functions). In this study, all the models were applied in the same conditions (some original model structures were modified to match 
Table 2. Models studied, with their identification number, number of optimized parameters and main reference.

\begin{tabular}{rlrl}
\hline ID & Model & $\begin{array}{r}\text { Number of } \\
\text { optimized } \\
\text { parameters }\end{array}$ & \\
& & Derived from \\
\hline 1 & GR4J & 4 & Perrin et al. (2003) \\
2 & HBV0 & 9 & Bergström et al. (1973) \\
3 & GR3J & 3 & Berthet et al. (2009) \\
4 & WAGE & 8 & Warmerdam et al. (1997) \\
5 & PDM0 & 8 & Moore et al. (1981) \\
6 & MORD & 6 & Garçon (1999) \\
7 & CREC & 8 & Cormay et al. (1973) \\
8 & TANK & 10 & Sugawara (1979) \\
9 & SMAR & 9 & O'Connell et al. (1981) \\
10 & TOPM & 8 & Michel et al. (2003) \\
11 & HYM0 & 6 & Yadav et al. (2007) \\
12 & CEQU & 9 & Girard et al. (1972) \\
13 & IHAC & 6 & Jakeman et al. (1990) \\
14 & SIMH & 8 & Chiew et al. (2002) \\
15 & MOHY & 7 & Fortin et al. (2006) \\
16 & SACR & 13 & Burnash et al. (1973) \\
\hline
\end{tabular}

the test framework): they were run at a daily time step, using the same rainfall and potential evapotranspiration inputs, and were calibrated with the same optimization procedure using the local search procedure described by Edijatno et al. (1999), applied in combination with a pre-screening of the parameter space as proposed by Mathevet (2005). The objective function was the root mean square error. Note that the objective here is not to test the original structures and compare them, but rather to have a variety of conceptualizations to build ensemble flow predictions that account for uncertainties in the structure of lumped hydrological models. Most of these models were previously tested by Perrin et al. (2001) and detailed presentations are provided by Mathevet (2005). It is out of the scope of this article to present the models and full descriptions of each model structure can be found in the references listed in Table 2.To avoid confusion with the original model from which they are derived, only 4 letter acronyms are used.

\subsection{Experimental setup}

Flow forecasting was performed in two steps:

1. the models were individually calibrated and validated for each watershed, based on the available observations;

2. the 12:00 UTC ECMWF meteorological deterministic forecasts (M-DPS) and the ensemble prediction system (M-EPS) were used to predict daily streamflows up to 9 days ahead over 507 days from March 2005 to July 2006 (period not used in calibration). The assimilation of observed flow data was done by a simple objective output updating based on Refsgaard (1997).

Three types of hydrological ensemble prediction sets $(\mathrm{H}-$ EPS) were constructed, consisting of 16,50 , and $800 \mathrm{mem}-$ bers (Table 3):

- The 16-member ensemble is obtained by running all 16 hydrological models with the deterministic meteorological forecast as input. Each catchment has thus $1 \mathrm{H}-\mathrm{EPS}$ of 16 members. An average performance per catchment is calculated over the evaluation period and the mean value over all catchments is considered.

- The 50-member ensemble consists of using the 50 perturbed forecasts from the M-EPS as input to each individual hydrological model. Each catchment has thus $16 \mathrm{H}$-EPS of 50 members. For each model, the corresponding H-EPS is evaluated at each catchment, resulting on an average performance per catchment over the evaluation period. An average value (mean over the 29 catchments) is obtained for each model. The 16 scores obtained are graphically depicted by box plots.

- In the 800-member ensemble, all 16 models are driven by the 50 forecast members from the M-EPS and all the outputs are considered as a single ensemble. Each catchment has thus $1 \mathrm{H}$-EPS of 800 members. An average performance per catchment is calculated over the evaluation period and the mean value over all catchments is considered.

The simple model average method (Shamseldin et al., 1997) was used to combine the 16 -member and the 800 -member ensembles to obtain one single value of each type of ensemble, so they can be compared with the single-model deterministic forecast obtained with the M-DPS.

\subsection{Performance and reliability}

The evaluation of the performance of the deterministic simulations is based on the absolute error (AE). The performance of the probabilistic simulations was assessed with the Continuous Ranked Probability Score (CRPS), (Matheson and Winkler, 1976). The main advantage of these two scores is that they can be directly compared (Gneiting and Raftery, 2007). It thus provides a simplified way to compare the performance of ensemble simulations against the performance of deterministic simulations, for each individual catchment. An analytical solution to obtain the value of the integral defining the CRPS was proposed by Gneiting and Raftery (2007) and applied for normal predictive distributions. In this study, a Monte-Carlo approximation was used with a gamma distribution adjusted to the predictive function. In order to compare the different catchments, a Skill Score of the mean CRPS (here, $\mathrm{SS}_{\mathrm{CRPS}}$ ) was calculated using the climatology as reference (Wilks, 1995). 
Table 3. Scenarios of hydrological ensemble predictions (H-EPS) tested in this study, based on 16 hydrological models, and deterministic (M-DPS) and probabilistic (M-EPS) rainfall forecasts.

\begin{tabular}{lll}
\hline & \multicolumn{2}{c}{ Meteorological Forecast } \\
\hline $\begin{array}{l}\text { Hydrological } \\
\text { models }\end{array}$ & M-DPS & M-EPS \\
(Deterministic) & (Probabilistic) \\
\hline Individual & Deterministic forecast (H-DPS) & 50-member ensemble \\
All & 16-member ensemble & 800-member ensemble \\
\hline
\end{tabular}

Reliability refers to the statistical consistency between simulations and observations. For instance, a reliable $90 \%$ confidence interval calculated using the predictive distribution function should, on average, contain the observed value in 9 cases out of 10 . In this study, the reliability diagram was used to evaluate reliability. It is a graphical approach to represent the performance of probability simulations of dichotomous events (Wilks, 1995). Nine confidence intervals were verified, ranging from $10 \%$ to $90 \%$. For each forecast, it was established whether or not the observation was included in the confidence intervals. This operation was repeated for all forecast-observation pair, so the mean effective coverage may be drawn against the nominal ones.

The relative operating characteristic (ROC) curve (Peterson et al., 1954; Mason, 1982) plots the probability of detection (POD) versus the probability of false detection (POFD). The POD is the fraction of the observed "yes" events that were correctly forecasted. The POFD is the fraction of the observed "no" events that were incorrectly forecasted. The area under the ROC curve characterizes the quality of a simulation system's ability to correctly anticipate the occurrence or non occurrence of the events. The ROC area ranges from 0 to $1,0.5$ indicating no skill and 1 being the perfect score. ROC measures the ability of the simulation to discriminate between two alternative outcomes, thus measuring resolution. It is not sensitive to bias in the simulation and thus gives no information about reliability.

\section{Results}

Before comparing the hydrological ensembles, the performance and reliability of the meteorological ensembles and the diversity of the lumped models are assessed. The analysis of the precipitation forecasts from the ECMWF M-EPS (not shown) revealed that the performance for all 29 catchments decreases, as expected, with increasing lead time, while reliability was achieved for lead times greater or equal to 3 days. For each lumped model, the 50-member MAE values are evaluated for all catchments and forecast lead times (Fig. 2). Results show that the models differ in performance; however, none is clearly better or worse than all the others. Note that Table 2 applies the model ordering given by Fig. 2 .

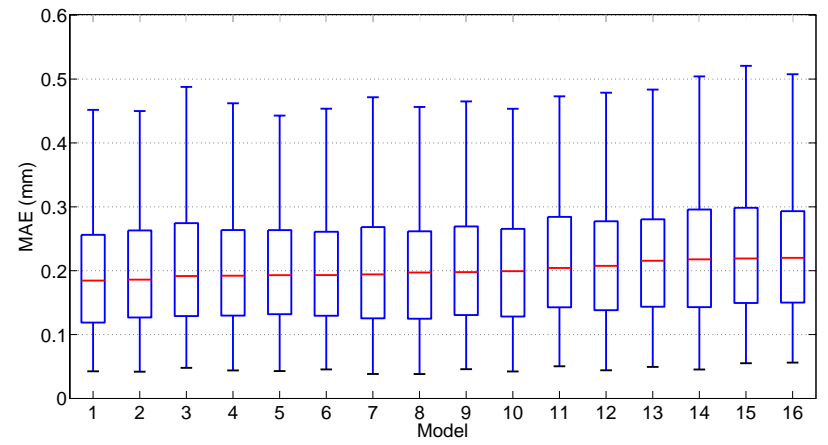

Fig. 2. Mean absolute error (MAE) calculated for the 16 lumped hydrological models and for all forecast lead times (1 to 9 days) over a 17 -month period and for the 29 studied catchments. The box has lines at the lower, median, and upper quartile values (IQR) and whiskers extend to $1.5 \times \mathrm{IQR}$.

Is there more valuable information in the H-EPS than in the deterministic predictions, when comparing MAE and mean CRPS values? Results obtained for each catchment confirm the superiority of the H-EPS, as illustrated by the example given in Fig. 3 for the Moselle River at Hauconcourt (catchment A7930610 with an upstream area of $9387 \mathrm{~km}^{2}$ ), where the mean CRPS is lower than the MAE. When looking at the results in details, best results are achieved for the MAE (deterministic) and for the mean CRPS (probabilistic) when all 800 members are considered. The 16-member ensemble (driven by the deterministic forecasts) is competitive up to lead times of about 3 days. For these shorter lead times, the 50-member ensemble, where individual models are driven by ensemble predictions, clearly underperforms. For longer lead times, however, some individual models driven by the M-EPS perform better than the 16-member ensemble (as can be seen as the box plots of the 50 -member ensemble cross the line representing the 16-member ensemble prediction), although individual M-EPS models are rarely as good as the 800-member ensemble. These findings are confirmed by Fig. 4, where the mean $\mathrm{SS}_{\mathrm{CRPS}}$ over all catchments is plotted. The 16-member multi-model approach (several models driven by deterministic forecasts) is again skilful up to about a lead time of 3 days, after which the inclusion of uncertainties arising from the prediction of rainfall becomes 
a)

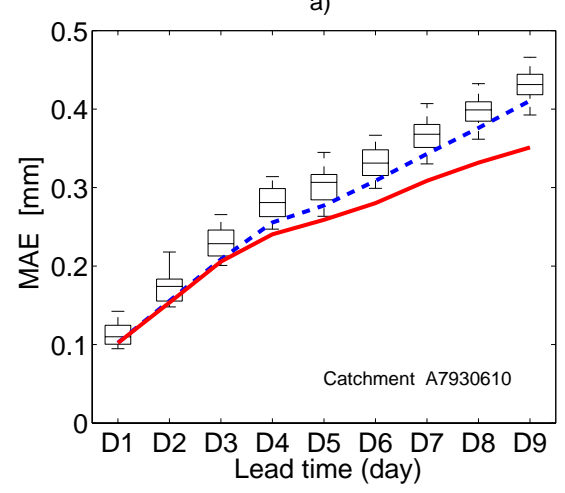

b)

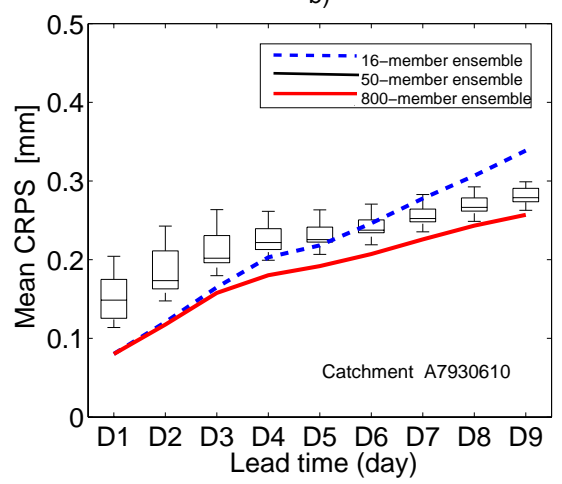

Fig. 3. Example of MAE and CRPS values for a given catchment $\left(A 793061\right.$ : Moselle River at Hauconcourt; area $\left.=9387 \mathrm{~km}^{2}\right)$ and three types of ensemble predictions.

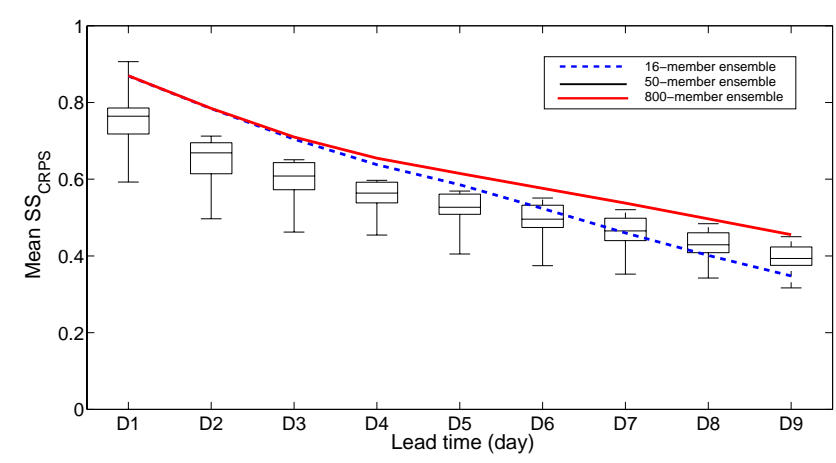

Fig. 4. Mean $\mathrm{SS}_{\mathrm{CRPS}}$ as a function of lead time for the 29 studied catchments and three types of ensemble predictions.

beneficial. We note that this threshold of 3 days is coherent with the catchments' mean characteristic response time scale of 3.2 days, linked to flow dynamics.

Reliability diagrams considering all 29 catchments are presented in Fig. 5 for five lead times. The reliability of the individual models driven by the M-EPS (box plots of the 50-member ensemble in Fig. 5) is very poor for short lead times ( 1 to 2 days) and slowly progresses with increasing lead time. Some of the individual models produce almost reliable predictive distributions only for a 9-day lead time. The situation is better for the 16-member ensembles, driven by the deterministic forecasts, especially for shorter lead times. However, their reliability worsens gradually beyond 5 days. Again, the 800-member ensembles show better skill, reaching reliability after a lead time of 5 days. It can be said that the 800-member ensembles provide higher spread and "correct" to some extent the under-dispersion of the H-EPS with smaller number of members. In order to have a glimpse of the spread of the forecasts composing each ensemble prediction set, an example of the hydrographs obtained for each type of H-EPS tested is presented in Fig. 6 for the 5-day lead time. The range of discharge predictions of the different ensembles is illustrated. The case presented (River Meurthe at Laneuveville-devant-Nancy with upstream area of $2780 \mathrm{~km}^{2}$ ) is representative of other catchments: the 800-member ensemble shows the largest dispersion.

Finally, the ROC score is used to evaluate the resolution of the predictive distributions, i.e., their ability to discriminate between two alternative outcomes (events and no events) of large flood events. Figure 7 shows the mean ROC score of all 29 catchments calculated for threshold values corresponding to the quantile $90 \%$ of the observed streamflow time series. ROC scores for the 800-member ensemble are the highest for all forecast lead times, showing that this type of H-EPS better manages to discriminate between large events and nonevents. The skill of the 16-member ensemble deteriorates more rapidly with increasing lead time, while the skill of the 50-member ensembles (box plots in the figure) is more invariant. Some models from the 50-member ensemble outperform the 16-member ensemble in terms of skill beyond a lead time of 3 days, while basically all models show higher skill after 7 days of lead time.

\section{Conclusions}

Ensemble forecasting is becoming a common procedure for considering uncertainty in hydrological predictions. Of the many sources of uncertainty that may affect a hydrological prediction system, uncertainties from the rainfall forecasts and the structure of the hydrological model are usually pinpointed as the most crucial ones. This has lead to two popular methods of implementing hydrological ensembles: pooling the outputs of a group of hydrological models for accounting for the uncertainties related to the structure of the models and driving a hydrological model with an ensemble of rainfall predictions to account for uncertainties related to the main meteorological forcing in the rainfall-runoff transformation. This study used 16 lumped hydrological models and 9-day ECMWF ensemble rainfall forecasts to evaluate flow 

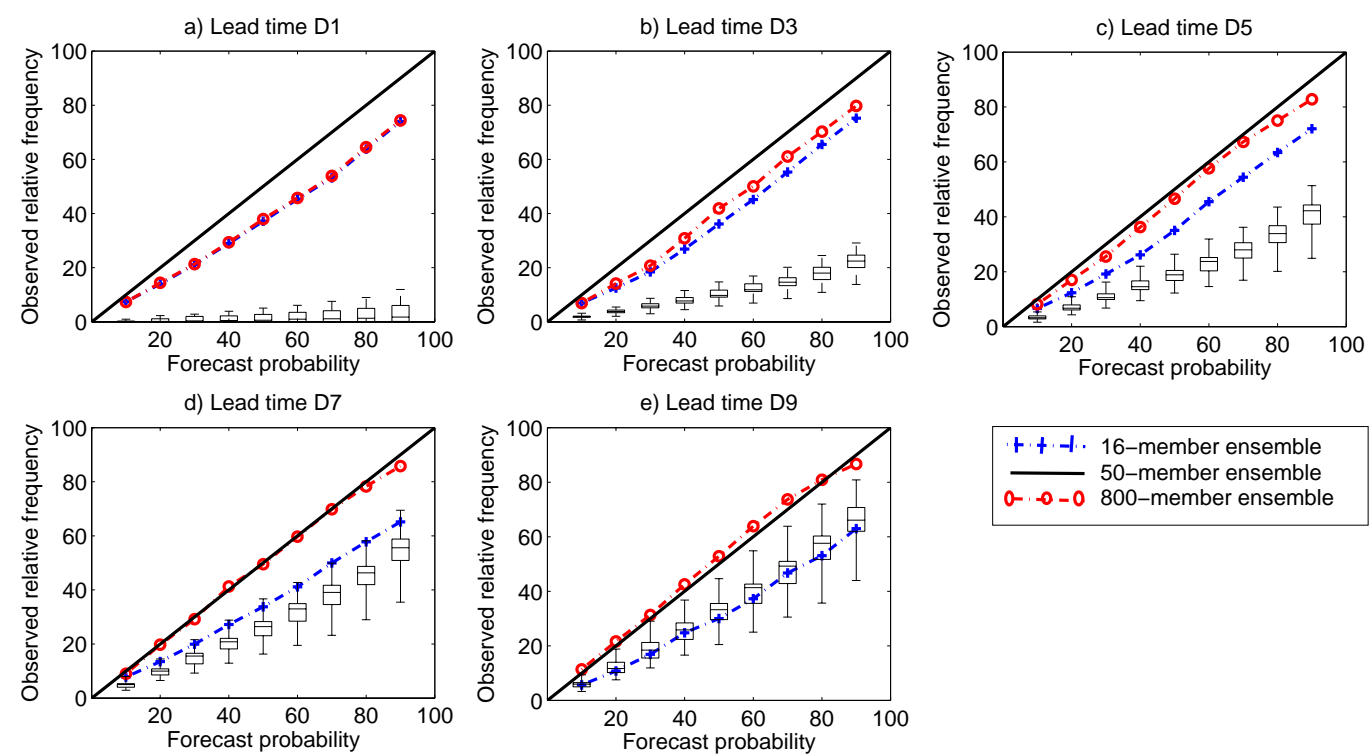

Fig. 5. Reliability Diagrams for the 29 studied catchments and lead times of (a) 1 day, (b) 3 days, (c) 5 days, (d) 7 days, and (e) 9 days, and for three types of ensemble predictions.
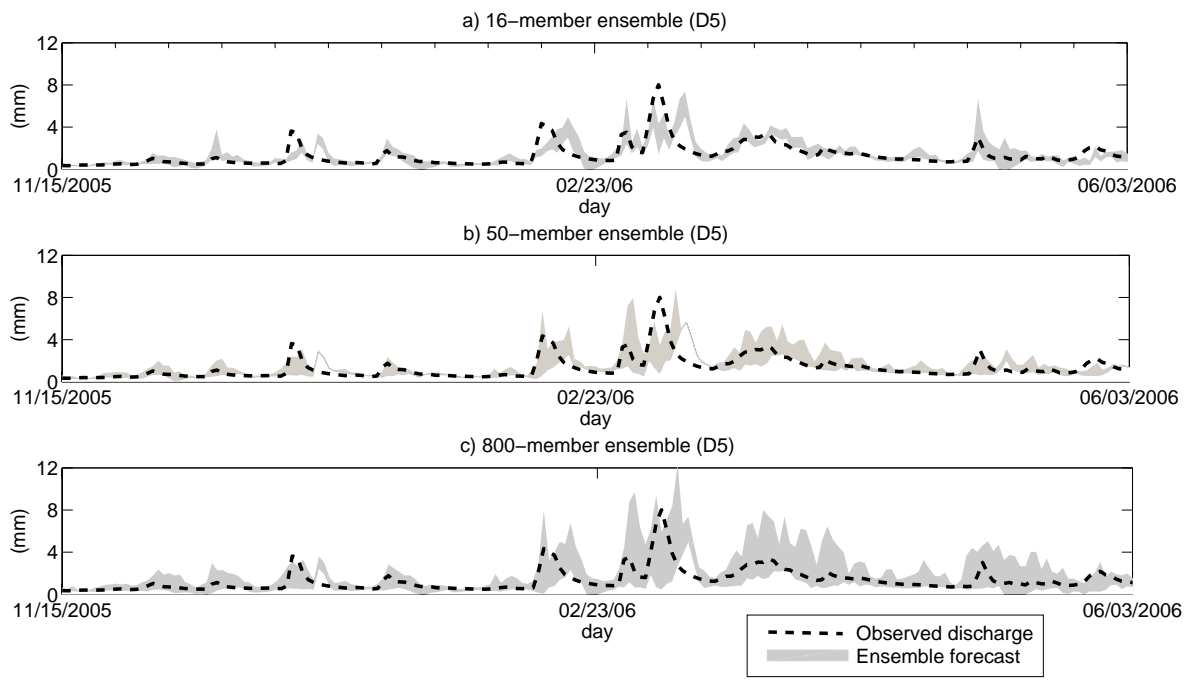

Fig. 6. Example of ensemble hydrographs (lead time 5 days) for a given catchment (A6921010: River Meurthe at Laneuveville-devantNancy; area $=2780 \mathrm{~km}^{2}$ ) and three types of ensemble predictions (areas in gray). Observed discharges are represented by tick lines.

ensemble predictions over 29 French catchments and a period of 507 days. This lead to three types of hydrological ensembles: a 16-member ensemble (driven by the deterministic prediction), a 50-member ensemble (driven by the M-EPS) and an 800-member ensemble that combines all hydrological models driven by the M-EPS. The two sources of uncertainty mentioned above (rainfall uncertainty and uncertainty from the structure of the hydrological model) were thus considered, either individually or collectively.
Results indicated that in general the skill of the hydrological ensembles diminishes with increasing lead time, while the reliability increases with increasing lead time. If the former is expected from any standard hydro-meteorological forecasting system, the latter shows that the ensembles assembled here started becoming reliable only for long lead times, if ever. Part of this difficulty may be inherited from the meteorological ensembles, which are not reliable prior to about a 3-day lead time. More importantly, it is believed that not including uncertainties associated with the hydrological initial conditions at the onset of the forecasts takes also its 


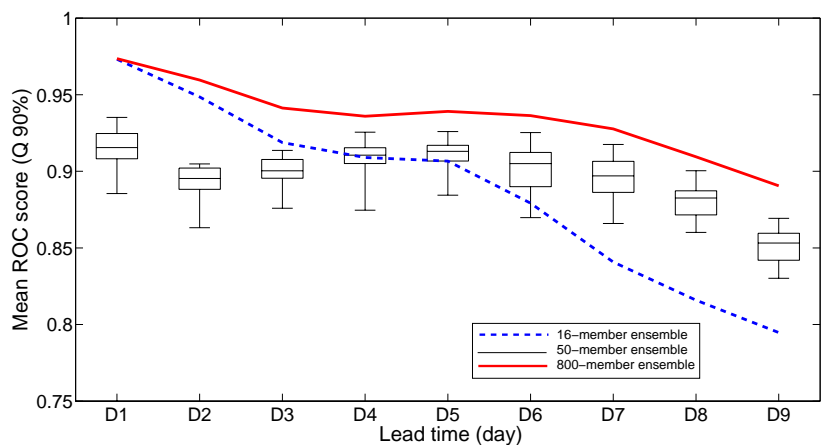

Fig. 7. Mean ROC score as a function of lead time for a flow threshold given by the Q90\% quantile for the 29 studied catchments and three types of ensemble predictions.

toll on reliability, at least for the first few time steps of the hydrological predictions.

As for the comparison per se between the three types of hydrological ensembles built here, the 800-member ensembles provide the most skilful solution for all lead times. Furthermore, it is the only system achieving reliability for some lead times (from 5 days ahead and on). There is thus a potential interest in combining sources of uncertainties. The 16-member ensembles show also comparable skill for the first lead times, but lose it more rapidly with increasing lead time than the 800-member ensembles. It appears that this approach is quite competitive up to about the mean characteristic response time scale of the studied catchments (3.2 days). It is also at around a lead time of 2 to 3 days that the 16-member ensembles are closest to achieving reliability. Even though the 16-member ensembles show some skill in the first lead times, these ensembles are the worse solution for discriminating between large events (flows exceeding the $90 \%$ quantile) and non-events, especially for lead times longer than 6 days. Performance of the 50-member ensembles varies from a lumped model to the other. In the best cases (best models), their skill and reliability surpass the one of the 16-member ensembles, notably for longer lead times. From the analysis of the reliability diagrams and the visualisation of the ensemble hydrographs, it also appeared that under-dispersion is indeed a major issue of hydrological ensembles built from M-EPS alone. The combination of MEPS and hydrological models (i.e. the 800 -member ensemble presented here) was the only reliable ensemble obtained in this study. Even if the performance and reliability of the 800 -member ensembles built here are quite satisfying, it may be too cumbersome and computer intensive to consider using this procedure for an operational implementation. Work is underway to test techniques for member selection in order to considerably reduce the number of ensemble members for operational hydrological forecasting, while conserving or improving the reliability and performance of the ensemble predictions.
Acknowledgements. The authors acknowledge the fruitful comments of two anonymous reviewers. The authors also acknowledge the Institut EDS, MITACS and CONACYT-México for their financial support and French MEEDM (Ministère de l'Écologie, de l'Energie, du Développement durable et de la Mer) for the hydrological data, Météo-France for the weather data, and F. Pappenberger and ECMWF for the rainfall forecasts.

Edited by: J. Thielen-del Pozo

Reviewed by: P. Burek and another anonymous referee

\section{References}

Bartholmes and Todini: Coupling meteorological and hydrological models for flood forecasting, Hydrol. Earth Syst. Sci., 9, 333 346, doi:10.5194/hess-9-333-2005, 2005.

Bergström, S. and Forsman, A.: Development of a conceptual deterministic rainfall-runoff model, Nord. Hydrol., 4, 147-1-70, 1973.

Berthet, L., Andréassian, V., Perrin, C., and Javelle, P.: How crucial is it to account for the antecedent moisture conditions in flood forecasting? Comparison of event-based and continuous approaches on 178 catchments, Hydrol. Earth Syst. Sci., 13, 819831, doi:10.5194/hess-13-819-2009, 2009.

Buizza, R., Miller, M., and Palmer, T. N.: Stochastic simulation of model uncertainties, Q. J. R. Meteorol. Soc., 125, 2887-2908, 1999.

Burnash, R. J. C., Ferral, R. L., and Mc Guire, R. A.: A generalized streamflow simulation system- Conceptual modeling for digital computers, U.S. Department of Commerce, National Weather Service and State of California, Department of Water Resources, 1973.

Chiew, F. H. S., Peel, M. C., and Western, A. W.: Application and testing of the simple rainfall-runoff model SIMHYD, in: Mathematical Models of Small Watershed Hydrology and Applications, edited by: Singh, V. P. and Frevret, D. K., Water Resources Publications, Highlands Ranch, 335-367, 2002.

Cormary, Y. and Guilbot, A.: Étude des relations pluie-débit sur trois bassins versants d'investigation, IAHS- AISH P., 108, 265279, 1973.

Cloke, H. L. and Pappenberger, F.: Ensemble flood forecasting: a review, J. Hydrol., 375, 613-626, 2009.

Davolio, S., Miglietta, M. M., Diomede, T., Marsigli, C., Morgillo, A., and Moscatello, A.: A meteo-hydrological prediction system based on a multi-model approach for precipitation forecasting, Nat. Hazards Earth Syst. Sci., 8, 143-159, doi:10.5194/nhess-8143-2008, 2008.

Dietrich, J., Schumann, A. H., Redetzky, M., Walther, J., Denhard, M., Wang, Y., Pfützner, B., and Büttner, U.: Assessing uncertainties in flood forecasts for decision making: prototype of an operational flood management system integrating ensemble predictions, Nat. Hazards Earth Syst. Sci., 9, 1529-1540, doi:10.5194/nhess-9-1529-2009, 2009.

Edijatno, Nascimento, N. O., Yang, X., Makhlouf, Z., and Michel, C.: GR3J: a daily watershed model with three free parameters, Hydrolog. Sci. J., 44(2), 263-277, 1999.

Fortin, V. and Turcotte, R.: Le modèle hydrologique MOHYSE, Note de cours pour SCA7420, Département des sciences de la terre et de l'atmosphère, Université du Québec à Montréal, 2006. 
Garçon, R.: Modèle global Pluie-Débit pour la prévision et la prédétermination des crues, La Houille blanche, 7(8), 88-95, 1999.

Georgakakos, K. P., Seo, D.-J., Gupta, H., Schaake, J., and Butts, M. B.: Characterizing streamflow simulation uncertainty through multimodel ensembles, J. Hydrol., 298, 222-241, 2004.

Girard, G., Morin G., and Charbonneau, R.: Modèle précipitationsdébits à discrétisation spatiale, Cahiers ORSTOM Série Hydrologie, IX 4, 35-52, 1972.

Gneiting, T. and Raftery, A. E.: Strictly proper scoring rules, prediction, and estimation, J. Am. Stat. Assoc., 102(477), 359-378, 2007.

He, Y., Wetterhall, F., Bao, H., Cloke, H., Li, Z., Pappenberger, F., Hu, Y., Manful, D., and Huang, Y.: Ensemble forecasting using TIGGE for the July-September 2008 floods in the Upper Huai catchment: a case study, Atmos. Sci. Lett., 11 (2), 132$138,2010$.

Hopson, T. and Webster, P.: A 1-10 day ensemble forecasting scheme for the major river basins of Bangladesh: forecasting severe floods of 2003-07, J. of Hydrometeorol., 11(3), 618-641, 2010.

Jakeman, A. J., Littlewood, I. G., and Whitehead, P. G.: Computation of the instantaneous unit hydrograph and identifiable component flows with applications to two small upland catchments, J. Hydrol., 117, 275-300, 1990.

Jaun, S. and Ahrens, B.: Evaluation of a probabilistic hydrometeorological forecast system, Hydrol. Earth Syst. Sci., 13, 10311043, doi:10.5194/hess-13-1031-2009, 2009.

Jaun, S., Ahrens, B., Walser, A., Ewen, T., and Schr, C.: A probabilistic view on the August 2005 floods in the upper Rhine catchment, Nat. Hazards Earth Syst. Sci., 8, 281-291, doi:10.5194/nhess-8-281-2008, 2008.

Kalas, M., Ramos, M. H., Thielen, J., and Babiakova, G.: Evaluation of the medium-range European flood forecasts for the March-April 2006 flood in the Morava River, J. Hydrol. Hydromech., 56(2), 116-132, 2008.

Krishnamurti, T. N.: Improved Weather and Seasonal Climate Forecasts from Multimodel Superensemble, Science, 285(1548), 1548-1550, 1999.

Mason, S. J.: A model for assessment of weather forecast, Aust. Met. Mag., 30, 291-303, 1982.

Matheson, J. E. and Winkler, R. L.: Scoring rules for continuous probability distributions, Manage Sci., 22, 1087-1096, 1976.

Mathevet, T.: Quels modèles pluie-débit globaux pour le pas de temps horaire? Développement empirique et comparaison de modèles sur un large échantillon de bassins versants, Ph.D. thesis, ENGREF (Paris), Cemagref (Antony), France, 463 pp., 2005.

Michel, C., Perrin, C., and Andréassian, V.: The exponential store: a correct formulation for rainfall-runoff modeling, Hydrolog. Sci. J., 48(1), 109-124, 2003.

Moore, R. J. and Clarke, R. T.: A distribution function approach to rainfall-runoff modeling, Water Resour. Res., 17(5), 1367-1382, doi:10.1029/WR017i005p01367, 1981.

O'Connell, P. E. and Clarke R. T.: Adaptative hydrological forecasting: A review, Hydrolog. Sci. Bulletin, 26(2), 179-205, 1981.

Olsson, J. and Lindström, G.: Evaluation and calibration of operational hydrological ensemble forecasts in Sweden, J. Hydrol., 350, 14-24, 2008.

Oudin, L., Hervieu, F., Michel, C., Perrin, C., Andréassian, V., An- ctil, F., and Loumagne, C.: Which potential evapotranspiration input for a rainfall-runoff model? Part 2 - Towards a simple and efficient PE model for rainfall-runoff modeling, J. Hydrol., 303(1-4), 290-306, 2005.

Pappenberger, F., Bartholmes, J., Thielen, J., Cloke, H., Buizza, R., and de Roo, A.: New dimensions in early flood warning across the globe using grand-ensemble weather predictions, Geophys. Res. Lett., 35, L10404, doi:10.1029/2008GL033837, 2008.

Park, Y. Y., Buizza, R., and Leutbecher, M.: TIGGE: preliminary results on comparing and combining ensembles, ECMWF TM 548, European Centre for Medium-Range Weather Forecasts (ECWMF), Reading, UK, 2007.

Perrin, C., Michel, C., and Andréassian, V.: Does a large number of parameters enhance model performance? Comparative assessment of common catchment model structures on 429 catchments, J. Hydrol., 242(3-4), 275-301, 2001.

Perrin, C., Michel, C., and Andréassian, V.: Improvement of a parsimonious model for streamflow simulation, J. Hydrol., 279, 275289, 2003.

Peterson, W. W., Birdsall, T. G., and Fox, W. C.: The theory of signal detectability, Trans. IRE Prof. Group. Inf. Theory, PGIT, 2-4, 171-212, 1954.

Quintana-Seguí, P., Le Moigne, P., Durand, Y., Martin, E., Habets, F., Baillon, M., Canellas, C., Franchisteguy, L., and Morel, S.: Analysis of near-surface atmospheric variables: Validation of the SAFRAN analysis over France, J. Appl. Meteorol. Climato., 47(1), 92-107, 2008.

Randrianasolo, A., Ramos M.H., Thirel G., Andréassian V., and Martin, E.: Comparing the scores of hydrological ensemble forecasts issued by two different hydrological models, Atmos. Sci. Lett., 11(2), 100-107, 2010.

Ranzi R., Bacchi B., Ceppi A., Cislaghi M., Ehret U., Jaun S., Marx A., Hegg C., and Zappa M.: Real-time demonstration of hydrological ensemble forecasts in MAP D-PHASE, La-HouilleBlanche, 5, 95-103, 2009.

Refsgaard, J. C.: Validation and intercomparison of different updating procedures for real-time forecasting, Nord. Hydrol., 28, 65-84, 1997.

Renner, M., Werner, M. G. F., Rademacher, S., and Sprokkereef, E.: Verification of ensemble flow forecast for the River Rhine, J. Hydrol., 376, 463-475, 2009.

Roulin, E. and Vannitsem, S.: Skill of medium-range hydrological ensemble predictions, J. Hydrometeorol., 6, 729-744, 2005.

Sauquet, E., Ramos, M.H., Chapel, L., and Bernardara, P.: Streamflow scaling properties: investigating characteristic scale from different statistical approaches, Hydrol. Processes, 22, 34623475, 2008.

Schaake, J. C., Hamill, T. M., Buizza, R., and Clark, M.: HEPEX: The hydrological ensemble prediction experiment, B. Am. Meteorol. Soc., 88(10), 1541-1547, 2007.

Shamseldin, A. Y., O'Connor, K. M., and Liang, G. C.: Methods for combining the outputs of different rainfall-runoff models, J. Hydrol., 197, 203-229, 1997.

Sugawara, M: Automatic calibration of the Tank Model, Hydrolog. Sci. J., 24(3), 375-388, 1979.

Thielen, J., Schaake J., Hartman R., and Buizza, R.: Aims, challenges and progress of the Hydrological Ensemble Prediction Experiment (HEPEX) following the third HEPEX workshop held in Stresa 27 to 29 June 2007, Atmos. Sci. Lett., 9(2), 29-35, 2008. 
Thielen, J., Bartholmes, J., Ramos, M.-H., and de Roo, A.: The European Flood Alert System Part 1: Concept and development, Hydrol. Earth Syst. Sci., 13, 125-140, doi:10.5194/hess-13-1252009, 2009.

Thirel, G., Rousset-Regimbeau, F., Martin, E., and Habets, F.: On the impact of short-range meteorological forecasts for ensemble stream flow predictions, J. Hydrometeorol., 9(6), 1301-1317, 2008.

Warmerdam, P. M., Khole, J., and Chormansky, J.: Modelling rainfall-runoff process in the Hupsele Breek research Bassin, Ecohydrological process in small basins, in: Proceedings of the Strasbourg Conference (24-26 September 1996), Tech. Doc. Hy., 14, 155-160, 1997.

Wilks, D. S.: Statistical Methods in the Atmospheric Sciences, Academic Press, 465 pp., 1995.

Yadav, M., Wagener, T., and Gupta, H.: Regionalization of constraints on expected watershed response behavior for improved predictions in ungauged basins, Adv. Water Resour., 30(8), 1756-1774, 2007.
Younis, J., Ramos M. H., and Thielen J.: EFAS forecasts for the March-April 2006 flood in the Czech part of the Elbe River Basin - a case study, Atmos. Sci. Lett., 9(2), 88-94, 2008.

Zappa, M., Rotach, M. W., Arpagaus, M., Dorninger, M., Hegg, C., Montani, A., Ranzi, R., Ament, F., Germann, U., Grossi, G., Jaun, S., Rossa, A., Vogt, S., Walser, A., Wehrhan, J., and Wunram, C.: MAP D-PHASE: Real-time demonstration of hydrological ensemble prediction systems, Atmos. Sci. Lett., 2, 80-87, 2008.

Zappa, M., Beven, K.J., Bruen, M., Cofino, A., Kok, K., Martin, E., Nurmi, P., Orfila, B., Roulin, E., Schröter, K., Seed, A., Stzurc, J., Vehviläinen, B., Germann, U., and Rossa, A.: Propagation of uncertainty from observing systems and NWP into hydrological models: COST-731 Working Group 2, Atmos. Sci. Lett., 2, 8391, 2010 . 